Epidemiology and Infection

cambridge.org/hyg

\section{Original Paper}

Cite this article: Domínguez A et al (2018). Effectiveness of antiviral treatment in preventing death in severe hospitalised influenza cases over six seasons. Epidemiology and Infection 146, 799-808. https://doi.org/ $10.1017 /$ S0950268818000663

Received: 10 October 2017

Revised: 1 February 2018

Accepted: 21 February 2018

First published online: 2 April 2018

\section{Key words:}

Adherence; adults; antiviral treatment; effectiveness; influenza

Author for correspondence:

A. Romero-Tamarit, E-mail: arantxa.romero. tamarit@gmail.com

\title{
Effectiveness of antiviral treatment in preventing death in severe hospitalised influenza cases over six seasons
}

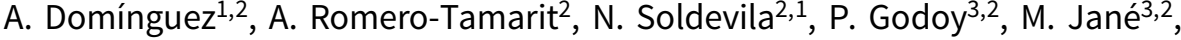 \\ A. Martínez ${ }^{3,2}$, N. Torner ${ }^{3,1,2}$, J.A. Caylà ${ }^{4,2}$, C. Rius ${ }^{4,2}$ and the Surveillance of \\ Hospitalized Cases of Severe Influenza in Catalonia Working Group
}

\footnotetext{
${ }^{1}$ Departament de Medicina, Universitat de Barcelona, Barcelona, Spain; ${ }^{2}$ CIBER Epidemiología y Salud Pública (CIBERESP), Madrid, Spain; ${ }^{3}$ Agència de Salut Pública de Catalunya, Generalitat de Catalunya, Barcelona, Spain and ${ }^{4}$ Agència de Salut Pública de Barcelona, Barcelona, Spain
}

\begin{abstract}
We investigated the predictors of neuraminidase inhibitor (NAI) treatment in severe hospitalised influenza cases and the association between antiviral treatment and mortality. An observational epidemiological study was carried out in Catalonia (Spain) during 2010-2016 in patients aged $\geqslant 18$ years. Severe hospitalised cases of laboratory-confirmed influenza requiring hospitalisation were included. We collected demographic, virological and clinical characteristics. Mixed-effects logistic regression was used to estimate crude and adjusted odds ratio (aOR). We included 1727 hospitalised patients, of whom 1577 (91.3\%) received NAI. Receiving NAI $\leqslant 48 \mathrm{~h}$ after onset of clinical symptoms (aOR $0.37,95 \%$ confidence interval (CI) $0.22-0.63$ ), $\leqslant 3$ days (aOR 0.49 , 95\% CI $0.30-0.79$ ) and $\leqslant 5$ days (aOR $0.50,95 \%$ CI $0.32-0.79)$ was associated with a reduction in deaths. In patients admitted to the intensive care unit (ICU) $(595 ; 34.5 \%)$, treatment $\leqslant 48 \mathrm{~h}$ (aOR $0.32,95 \%$ CI $0.14-0.74), \leqslant 3$ days (aOR $0.44,95 \%$ CI $0.20-0.97$ ) and $\leqslant 5$ days (aOR 0.45 , 95\% CI $0.22-0.96$ ) was associated with a reduction in deaths. Receiving treatment $>5$ days after onset of clinical symptoms was not associated with the reduction in deaths in hospitalised patients or those admitted to the ICU. NAI treatment of hospitalised patients with severe confirmed influenza was effective in avoiding death, mainly when administered $\leqslant 48 \mathrm{~h}$ after symptom onset, but also when no more than 5 days had elapsed.
\end{abstract}

\section{Introduction}

Influenza epidemics follow seasonal patterns that vary in distribution and severity and are associated with excess morbidity and mortality. Worldwide, these annual epidemics are estimated to result in about 3000 000-5000000 cases of severe illness, and between 300000 and 500000 deaths $[1,2]$. Pregnant women, small children, elderly people and anyone with medical risk conditions are at higher risk for severe infection and death. In industrialised countries, hospitalisation and death occur mainly in high-risk groups and most influenza-related deaths occur in people aged $\geqslant 65$ years. Therefore, influenza prevention and control remains a major challenge for public health systems worldwide [3].

Antiviral treatment with neuraminidase inhibitors (NAI) is considered an important adjunct to vaccination in order to reduce the risk of severe illness due to influenza among adults, particularly those with underlying medical risk conditions. Since the 2009 influenza A (H1N1) virus pandemic, both the United States Advisory Committee on Immunization Practices and the WHO recommend early, empirical antiviral treatment for those with suspected or confirmed influenza requiring hospitalisation or who have severe, progressive or complicated illness $[2,4]$. However, there are limited data on adherence to these recommendations in clinical practice [5], particularly among high-risk populations [6].

In Catalonia (Spain), antiviral treatment should be administered only to hospitalisedconfirmed cases of severe influenza and to hospitalised patients at risk of severe complications. Groups at high risk of complications include pregnant women and people with underlying medical conditions such as chronic lung disease (including asthma, cystic fibrosis and lung dysplasia); chronic cardiovascular disease (excluding hypertension); type I and type II diabetes; moderate-severe kidney impairment; haemoglobin and other haematologic disorders; liver impairment; immunosuppressive disorders; severe neuromuscular disorders and patients with morbid obesity (body mass index $(\mathrm{BMI})>40$ ) [7]. Antiviral treatment is not administered in primary care centres.

The efficacy of NAI in adults with risk factors for influenza complications has not been extensively evaluated [3]. Although a randomised clinical trial (RCT) confirmed that NAI 
reduce symptoms, no RCTs have examined the effectiveness of NAI against more serious outcomes [8]. However, an RCT does not fully inform on the effectiveness of a product as used in real clinical practice [9].

A systematic review of NAI by Michiels et al. concluded that there is no evidence of treatment benefits in elderly and at-risk individuals, vaccinated or not, on relevant outcomes such as hospitalisation and mortality [10].

In a meta-analysis by Hsu et al. of observational studies in any population that compared antiviral drugs with no antiviral treatment, earlier treatment was associated with significantly better outcomes in terms of avoiding hospitalisation and intensive care unit (ICU) admissions [11].

The suboptimal use of NAI in high-risk patients and the lack of confidence in their effectiveness in healthcare workers justify the need for studies on the effectiveness of antivirals on meaningful clinical endpoints in high-risk patients [12].

In October 2010, the Public Health Agency of Catalonia initiated the surveillance of severe hospitalised cases of influenza as a tool to complement information provided by the influenza sentinel system based on primary healthcare physicians. The objectives of this study were to investigate predictors of antiviral treatment in severe hospitalised influenza cases during six influenza seasons and the effect of early antiviral treatment in avoiding death.

\section{Material and methods}

\section{Study design}

We carried out an observational epidemiological study of the effect of NAI treatment in adult patients hospitalised due to severe acute respiratory influenza virus infection.

In 2010, a surveillance system for severe influenza was started in Catalonia, a region in the northeast of Spain with 7.5 million inhabitants, in order to (a) estimate the severity of seasonal influenza epidemics and their impact on health services according to the virological characteristics of influenza; (b) provide information to improve influenza prevention and control; and (c) identify risk groups for severity. The system includes 12 hospitals covering a total population of 4644543 (62\% of the Catalan population) that report on hospitalised cases of confirmed severe influenza in each influenza season. Epidemiological surveillance of severe hospitalised cases of influenza in Catalonia begins in the 40th week of the year and lasts until week 20 of the following year: the participating hospitals report severe hospitalised influenza cases to the corresponding epidemiological surveillance unit [13].

A severe hospitalised influenza case was defined as a severe case of laboratory-confirmed influenza virus infection that required hospitalisation (pneumonia, septic shock, multiorgan failure or any other severe condition, including ICU admission) or who developed clinical signs during hospitalisation for other reasons. The diagnosis was confirmed by PCR and/or culture of nasopharyngeal swabs [14].

Respiratory tract samples were processed at each hospital laboratory within $24 \mathrm{~h}$ of receipt. A $300 \mu \mathrm{l}$ aliquot was taken for total nucleic acid extraction and eluted in $25 \mu \mathrm{l}$ of RNase-free elution buffer using the automatic QIAsymphony system (Qiagen, Hilden, Germany) according to the manufacturer's instructions. Subsequently, two specific one-step multiplex real-time PCR using Stratagene Mx3000P QPCR Systems (Agilent Technologies, Santa Clara, CA, USA) were carried out for typing A/B influenza virus (sensitivity was 10 and 103 copies/ $\mu$ l, respectively) and subtyping influenza A virus (sensitivity was 102, 103 and 10 copies/ $\mu \mathrm{l}$ for $\mathrm{H} 1, \mathrm{H} 3$ and $\mathrm{H} 5 \mathrm{RNA}$, respectively) [15].

\section{Data collected}

Reported cases of laboratory-confirmed severe hospitalised influenza in persons aged $\geqslant 18$ years during six influenza seasons (2010-2011 to 2015-2016) were included.

For each reported case, we recorded the variables age, sex, chronic obstructive pulmonary disease (COPD), asthma, obesity (BMI $>40$ ), chronic renal disease, immunodeficiency (HIV infection or other), chronic cardiovascular disease, chronic liver disease, pregnancy, ICU admission, date of symptom onset, complications (secondary or primary pneumonia, acute respiratory distress syndrome and multiple organ failure), death, type of virus (A, B or C), seasonal influenza vaccination status and date and drug of NAI treatment.

Cases were considered vaccinated with the influenza vaccine if they had received a dose of the vaccine $\geqslant 14$ days before symptom onset.

The information for each study variable was collected by public health officers of the surveillance units of Catalonia through an epidemiological survey. The primary source of information was the medical record.

\section{Statistical analysis}

The demographic, virological and clinical characteristics of treated and untreated patients were compared using the $\chi^{2}$ test.

Associations between death and the independent variables, including NAI treatment (early treatment and late treatment compared with no treatment), were assessed in a bivariate analysis. Possible interactions between antiviral treatment and independent variables were analysed by logistic regression. Independent variables were checked for collinearity using the variance inflation factor [16].

Because the participant hospitals may not be homogeneous and there were differences in the number of deaths between hospitals, a mixed-effects logistic regression model with the variable hospital as a random intercept was constructed to estimate the crude and adjusted odds ratio (aOR) and their corresponding 95\% confidence interval (CI). To calculate the aOR, a multivariable analysis was made using the propensity scores, which were estimated by logistic regression with NAI treatment as the outcome and age, sex, COPD, asthma, obesity, chronic renal disease, immunodeficiency, chronic cardiovascular disease, chronic liver disease, pregnancy, seasonal influenza vaccination, type of virus and mismatches between circulating influenza strains and the components of the seasonal vaccine as independent variables. The propensity score was used as a continuous covariate in a final mixed-effects logistic regression model.

The analysis was performed using the SPSS v.24 statistical package and the R v3.3.0 statistical software (http://cran.r-project.org).

\section{Ethical considerations}

All data used in the analysis were collected as part of the routine public health surveillance activities and were therefore exempt from the institutional review board review. 
Table 1. Characteristics of influenza cases treated and untreated with neuraminidase inhibitors, Catalonia, 2010-2016

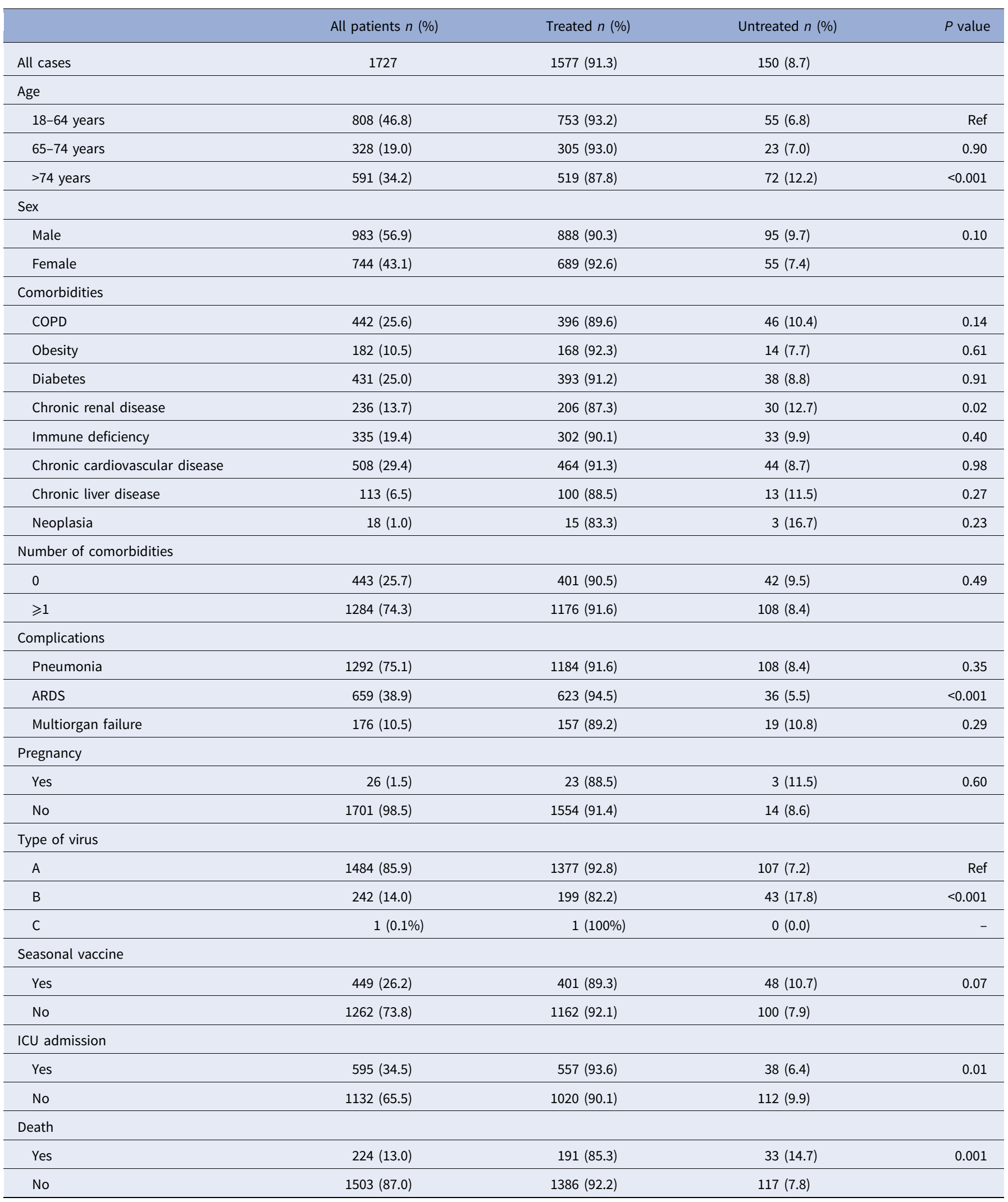

ARDS, acute respiratory distress syndrome; ICU, intensive care unit. 


\section{Results}

A total of 1727 hospitalised patients aged $\geqslant 18$ years were included during the study period, of whom $91.3 \%$ received NAI (oseltamivir $99.7 \%$, zanamivir $0.26 \%$ ). Demographic and clinical characteristics and influenza vaccination status are shown in Table 1. Patients aged 18-64 years, patients with respiratory distress syndrome, patients admitted to the ICU and patients who survived had the highest frequencies of NAI treatment.

The frequency of treatment by season is shown in Figure 1: the highest frequency of NAI treatment $(95.3 \%)$ was in the 20102011 season and the lowest $(78 \%)$ in the $2012-13$ season.

A total of 437 patients $(26.3 \%)$ received NAI treatment within $48 \mathrm{~h}$ of symptom onset, 649 (39.1\%) within 3 days and 1001 $(60.3 \%)$ within 5 days.

The seasons with mismatch were 2014-15 for the influenza A virus and 2011-12, 2013-14 and 2015-16 for the influenza B virus.

No interaction was found between NAI treatment and the other variables investigated, and there was no collinearity between the variables.

Death occurred in 224 patients (13\%): in the bivariate analysis, death was associated with age $\geqslant 65$ years, chronic renal disease, immunodeficiency, chronic cardiovascular disease, chronic liver disease and not receiving NAI (Table 2). In the multivariable analysis, factors associated with a reduction in deaths were: NAI treatment (aOR 0.56, 95\% CI 0.36-0.86), NAI treatment $\leqslant 48 \mathrm{~h}$ after symptom onset (aOR 0.37 , 95\% CI $0.22-0.63$ ), NAI treatment $\leqslant 3$ days after symptom onset (aOR 0.49 , 95\% CI $0.30-0.79$ ) and NAI treatment $\leqslant 5$ days after symptom onset (aOR 0.50 , $95 \%$ CI $0.32-0.79$ ) with respect to those who did not receive treatment (Table 4).

Of the 595 patients who required ICU admission, 128 (21.5\%) died: in the bivariate analysis, death was associated with age $\geqslant 65$ years, chronic renal disease, immunodeficiency, chronic cardiovascular disease, chronic liver disease and not receiving NAI treatment (Table 3). In the multivariable analyses, NAI treatment $\leqslant 48 \mathrm{~h}$ after symptom onset (aOR 0.32 , 95\% CI $0.14-0.74$ ), NAI treatment $\leqslant 3$ days after symptom onset (aOR $0.44,95 \%$ CI $0.20-0.97)$ and NAI treatment $\leqslant 5$ days after symptom onset (aOR 0.45 , 95\% CI $0.22-0.96$ ) with respect to those who did not receive treatment were associated with a reduction in deaths.

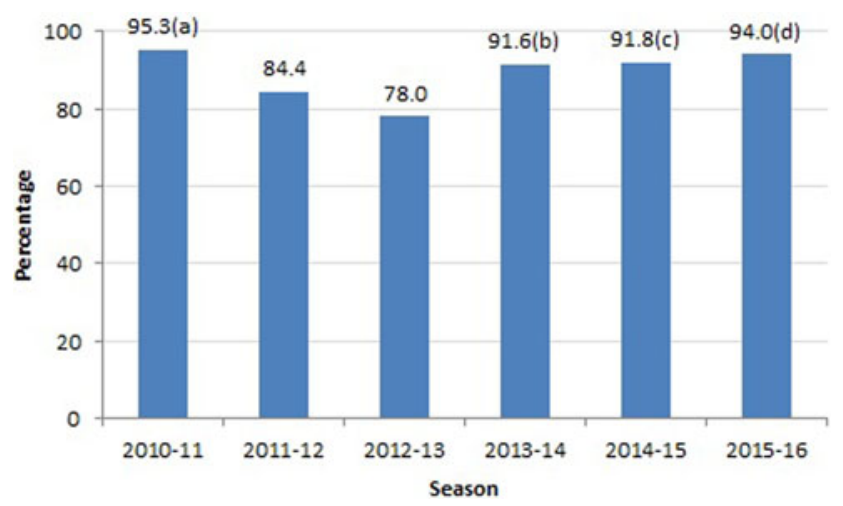

Fig. 1. Frequency of NAl treatment according to influenza season. NAls, neuraminidase inhibitors. (a) Highest values were observed for influenza A, NO multiorgan failure and survival patients. (b) Highest values were observed for NO chronic renal failure. (c) Highest values were observed for influenza A, acute respiratory distress syndrome, NO pneumonia and survival. (d) Highest values were observed for influenza A, acute respiratory distress syndrome and survival.
Treatment $>5$ days after symptom onset was not associated with a reduction in deaths in all hospitalised patients (aOR 0.63, 95\% CI $0.39-1.02$ ) or in patients admitted to the ICU (aOR 0.60, 95\% CI $0.28-1.29$ ) (Table 4).

The distribution of antiviral treatment, deaths and ICU admission by hospital and by season is shown in Supplementary Tables S1 and S2 and the crude OR and aOR of NAI in reducing deaths in different subgroups of patients are shown in Supplementary Table S3.

\section{Discussion}

This study, based on the surveillance of severe hospitalised patients with laboratory-confirmed influenza in the 2010-2011 to 2015-2016 seasons in Catalonia, found a high frequency of patients receiving NAI and suggests that NAI treatment was effective in reducing the risk of death. The results also suggest a certain dose-response relationship between the effectiveness of NAI treatment in avoiding death and the time from symptom onset to the initiation of NAI treatment.

The frequency of hospitalised patients who received NAI treatment during the whole period was $91.3 \%$, slightly higher than the $86 \%$ observed in a study of adults hospitalised with laboratoryconfirmed influenza in the USA in the 2010-2011 to 20142015 seasons [17] and the 70\% observed in another Spanish study in the 2010-2011 season [18], but lower than the $96.2 \%$ of hospitalised patients in the Japanese study by Maruyama et al. during the 2010-2013 influenza seasons [19]. In Japan, NAI is recommended for patients with a positive rapid diagnostic antigen test, which may explain the high level of treatment adherence.

We found that $93.6 \%$ of patients admitted to the ICU received NAI, very close to the $94.8 \%$ found in a US study during the 2013-2014 season [20] and higher than the $85.8 \%$ observed in patients of all ages admitted to the ICU in China by Xu et al. in the 2010-11 season. We observed a decrease in the proportion of patients who began NAI treatment within 2 days after onset symptom according to disease severity $(26.3 \%$ in all severe hospitalised patients, $23.7 \%$ in patients admitted to the ICU and $17.2 \%$ in patients who died), as was also observed in the study by $\mathrm{Xu}$ et al. [21] (34.6\% in moderately ill patients, $17.5 \%$ patients admitted to the ICU and $14.3 \%$ in patients who died).

Patients aged $\geqslant 75$ years received NAI less frequently (87.8\%) than those aged 18-64 years (93.2\%) in our study, in contrast to the study by Rolfes et al. [22] in a Connecticut (USA) tertiary hospital, in which adults aged $\geqslant 75$ years were more frequently prescribed NAI than younger patients during the 2010-2011 to 2012-13 seasons. In the study by Lindegren et al. in four US hospitals, carried out from 2006 to 2012 in laboratory-confirmed cases, NAI treatment was more common in patients aged $\geqslant 65$ years than in those aged 50-64 years, although the differences were not statistically significant [6].

In agreement with other authors $[6,22]$, we found no association between comorbidities and receiving NAI treatment. In contrast, Appiah et al. [17] in an all-ages study found that patients with comorbidities more frequently received antivirals than those without.

We found that a higher proportion of influenza A cases received NAI than influenza B cases $(92.8 \%$ vs. $82.2 \%, P<$ 0.001). In the 2010-2011 Spanish study by Gutiérrez-Pizarraya et al. patients with confirmed influenza A virus who presented primary pneumonia had received NAI more frequently that 
Table 2. Factors associated with death in hospitalised patients, Catalonia, 2010-2016

\begin{tabular}{|c|c|c|c|c|c|}
\hline & All patients $(N=1727)$ & Death $(N=224)$ & No death $(N=1503)$ & Crude OR $(95 \% \mathrm{CI})$ & $P$ value \\
\hline $18-64$ years & $808(46.8 \%)$ & $74(33.0 \%)$ & $734(48.8 \%)$ & Ref & \\
\hline $65-74$ years & $328(19.0 \%)$ & $58(25.9 \%)$ & $270(18.0 \%)$ & $2.17(1.49-3.16)$ & $<0.001$ \\
\hline$\geqslant 75$ years & $591(34.2 \%)$ & $92(41.1 \%)$ & $499(33.2 \%)$ & $1.91(1.36-2.66)$ & $<0.001$ \\
\hline \multicolumn{6}{|l|}{ Sex } \\
\hline Male & $983(56.9 \%)$ & $137(61.2 \%)$ & $846(56.3 \%)$ & Ref & \\
\hline \multicolumn{6}{|l|}{ COPD } \\
\hline Yes & $442(25.6 \%)$ & $67(29.9 \%)$ & $375(25.0 \%)$ & $1.31(0.95-1.79)$ & 0.09 \\
\hline No & $1285(74.4 \%)$ & $157(70.1 \%)$ & $1128(75.0 \%)$ & Ref & \\
\hline \multicolumn{6}{|l|}{ Diabetes } \\
\hline Yes & $431(25.0 \%)$ & $60(26.8 \%)$ & $371(24.7 \%)$ & $1.14(0.82-1.56)$ & 0.43 \\
\hline No & $1296(75.0 \%)$ & $164(73.2 \%)$ & 1132 (75.3\%) & Ref & \\
\hline \multicolumn{6}{|c|}{ Chronic renal disease } \\
\hline Yes & $236(13.7 \%)$ & 49 (21.9\%) & $187(12.4 \%)$ & $1.86(1.30-2.66)$ & $<0.001$ \\
\hline No & $1491(86.3 \%)$ & $175(78.1 \%)$ & $1316(87.6 \%)$ & Ref & \\
\hline \multicolumn{6}{|c|}{ Immune deficiency } \\
\hline Yes & 335 (19.4\%) & 77 (34.4\%) & $258(17.2 \%)$ & $2.29(1.67-3.15)$ & $<0.001$ \\
\hline \multicolumn{6}{|c|}{ Chronic liver disease } \\
\hline No & 1614 (93.5\%) & $199(88.8 \%)$ & 1415 (94.1\%) & Ref & \\
\hline \multicolumn{6}{|l|}{ Neoplasia } \\
\hline Yes & $18(1.0 \%)$ & $3(1.3 \%)$ & $15(1.0 \%)$ & $1.27(0.35-4.57)$ & 0.72 \\
\hline No & 1709 (99.0\%) & $221(98.7 \%)$ & $1488(99.0 \%)$ & Ref & \\
\hline \multicolumn{6}{|l|}{ Pregnancy } \\
\hline Yes & $26(1.5 \%)$ & $0(0.0 \%)$ & $26(1.7 \%)$ & - & - \\
\hline No & 1701 (98.5\%) & $224(100 \%)$ & 1477 (98.3\%) & & \\
\hline \multicolumn{6}{|l|}{ Type of virus } \\
\hline A & $1484(85.9 \%)$ & $193(86.2 \%)$ & $1291(85.9 \%)$ & Ref & \\
\hline B & $242(14.0 \%)$ & $31(13.8 \%)$ & $211(14.0 \%)$ & $1.03(0.68-1.55)$ & 0.89 \\
\hline C & $1(0.1 \%)$ & $0(0.0 \%)$ & $1(0.1 \%)$ & - & \\
\hline \multicolumn{6}{|c|}{ Seasonal vaccine } \\
\hline Yes & $1262(73.8 \%)$ & $63(28.3 \%)$ & $386(25.9 \%)$ & $1.18(0.86-1.63)$ & 0.30 \\
\hline No & $449(26.2 \%)$ & $160(71.7 \%)$ & 1102 (74.1\%) & Ref & \\
\hline \multicolumn{6}{|l|}{ NAI treatment } \\
\hline Yes & 1577 (91.3\%) & $191(85.3 \%)$ & $1386(92.2 \%)$ & $0.50(0.33-0.76)$ & 0.001 \\
\hline
\end{tabular}


Table 2. (Continued.)

\begin{tabular}{|c|c|c|c|c|c|}
\hline & All patients $(N=1727)$ & Death $(N=224)$ & No death $(N=1503)$ & Crude OR $(95 \% \mathrm{Cl})$ & $P$ value \\
\hline No & $150(8.7 \%)$ & $33(14.7 \%)$ & $117(7.8 \%)$ & Ref & \\
\hline \multicolumn{6}{|l|}{ NAI treatment } \\
\hline$\leqslant 48 \mathrm{~h}$ symptom onset & $437(26.3 \%)$ & $37(17.2 \%)$ & $400(27.7 \%)$ & $0.33(0.20-0.56)$ & $<0.001$ \\
\hline$>48 \mathrm{~h}$ symptom onset & $1074(64.7 \%)$ & $145(67.4 \%)$ & $929(64.2 \%)$ & $0.55(0.36-0.85)$ & 0.007 \\
\hline$\leqslant 3$ days symptom onset & $649(39.1 \%)$ & $70(32.6 \%)$ & $579(40.0 \%)$ & $0.43(0.27-0.69)$ & $<0.001$ \\
\hline$>3$ days symptom onset & $862(51.9 \%)$ & $112(52.1 \%)$ & $750(51.9 \%)$ & $0.53(0.34-0.82)$ & 0.004 \\
\hline No & $150(9.0 \%)$ & $33(15.3 \%)$ & $117(8.1 \%)$ & Ref & \\
\hline \multicolumn{6}{|l|}{ NAI treatment } \\
\hline \multicolumn{6}{|l|}{ NAI treatment } \\
\hline$\leqslant 5$ days symptom onset & $1001(60.3 \%)$ & $111(51.6 \%)$ & $890(61.5 \%)$ & $0.44(0.29-0.69)$ & $<0.001$ \\
\hline$>5$ days symptom onset & $510(30.7 \%)$ & $71(33.0 \%)$ & 439 (30.4\%) & $0.57(0.36-0.91)$ & 0.02 \\
\hline No & $150(9.0 \%)$ & $33(15.3 \%)$ & $117(8.1 \%)$ & Ref & \\
\hline
\end{tabular}

$\mathrm{NAl}$, neuraminadase inhibitors.

Table 3. Factors associated with death in patients admitted to the intensive care unit, Catalonia, 2010-2016

\begin{tabular}{|c|c|c|c|c|c|}
\hline & All patients $(N=595)$ & Death $(N=128)$ & No death $(N=467)$ & Crude OR $(95 \% \mathrm{CI})$ & $P$ value \\
\hline \multicolumn{6}{|l|}{ Age } \\
\hline $18-64$ years & $369(62.0 \%)$ & $58(45.3 \%)$ & $311(66.6 \%)$ & Ref & \\
\hline $65-74$ years & $118(19.8 \%)$ & 39 (30.5\%) & 79 (16.9\%) & $2.65(1.64-4.28)$ & $<0.001$ \\
\hline$\geqslant 75$ years & $108(18.2 \%)$ & $31(24.2 \%)$ & 77 (16.5\%) & $2.15(1.30-3.57)$ & 0.003 \\
\hline Male & $372(62.5 \%)$ & 89 (69.5\%) & $283(60.6 \%)$ & Ref & \\
\hline \multicolumn{6}{|l|}{ COPD } \\
\hline Yes & $161(27.1 \%)$ & $41(32.0 \%)$ & $120(25.7 \%)$ & $1.36(0.89-2.09)$ & 0.15 \\
\hline No & $434(72.9 \%)$ & $87(68.0 \%)$ & $347(74.3 \%)$ & Ref & \\
\hline \multicolumn{6}{|l|}{ Obesity } \\
\hline \multicolumn{6}{|l|}{ Diabetes } \\
\hline Yes & $145(24.4 \%)$ & $35(27.3 \%)$ & $110(23.6 \%)$ & $1.21(0.77-1.89)$ & 0.40 \\
\hline No & $450(75.6 \%)$ & $93(72.7 \%)$ & $357(76.4 \%)$ & Ref & \\
\hline \multicolumn{6}{|c|}{ Chronic renal disease } \\
\hline Yes & 78 (13.1\%) & $27(21.1 \%)$ & $51(10.9 \%)$ & $2.12(1.26-3.58)$ & 0.005 \\
\hline No & $517(86.9 \%)$ & $101(78.9 \%)$ & $416(89.1 \%)$ & Ref & \\
\hline \multicolumn{6}{|c|}{ Immune deficiency } \\
\hline Yes & $128(21.5 \%)$ & $47(36.7 \%)$ & $81(17.3 \%)$ & $2.72(1.75-4.22)$ & $<0.001$ \\
\hline
\end{tabular}


Table 3. (Continued.)

\begin{tabular}{|c|c|c|c|c|c|}
\hline & All patients $(N=595)$ & Death $(N=128)$ & No death $(N=467)$ & Crude OR $(95 \% \mathrm{CI})$ & $P$ value \\
\hline \multicolumn{6}{|l|}{ Chronic cardiovascular disease } \\
\hline Yes & $156(26.2 \%)$ & $44(34.4 \%)$ & $112(24.0 \%)$ & $1.64(1.07-2.50)$ & 0.02 \\
\hline No & $439(73.8 \%)$ & $84(65.6 \%)$ & $355(76.0 \%)$ & Ref & \\
\hline \multicolumn{6}{|l|}{ Chronic liver disease } \\
\hline Yes & $52(8.7 \%)$ & $19(14.8 \%)$ & $33(7.1 \%)$ & $2.21(1.19-4.08)$ & 0.01 \\
\hline No & $543(91.3 \%)$ & $109(85.2 \%)$ & $434(92.9 \%)$ & Ref & \\
\hline \multicolumn{6}{|l|}{ Neoplasia } \\
\hline Yes & $9(1.5 \%)$ & $3(2.3 \%)$ & $6(1.3 \%)$ & $1.84(0.44-7.72)$ & 0.40 \\
\hline No & $586(98.5 \%)$ & $125(97.7 \%)$ & $461(98.7 \%)$ & Ref & \\
\hline \multicolumn{6}{|l|}{ Pregnancy } \\
\hline Yes & $16(2.7 \%)$ & $0(0.0 \%)$ & $16(3.4 \%)$ & - & - \\
\hline No & $579(97.3 \%)$ & $128(100 \%)$ & $451(96.6 \%)$ & & \\
\hline \multicolumn{6}{|l|}{ Type of virus } \\
\hline A & $520(87.4 \%)$ & $112(87.5 \%)$ & $408(87.4 \%)$ & Ref & \\
\hline B & $75(12.6 \%)$ & $16(12.5 \%)$ & $59(12.6 \%)$ & $0.99(0.55-1.80)$ & 0.99 \\
\hline \multicolumn{6}{|l|}{ Seasonal vaccine } \\
\hline Yes & $107(18.1 \%)$ & $25(19.5 \%)$ & $82(17.7 \%)$ & $1.16(0.70-1.92)$ & 0.57 \\
\hline No & $483(81.9 \%)$ & $103(80.5 \%)$ & $380(82.3 \%)$ & Ref & \\
\hline \multicolumn{6}{|l|}{ NAI treatment } \\
\hline Yes & $557(93.6 \%)$ & $114(89.1 \%)$ & $443(94.9 \%)$ & $0.42(0.21-0.86)$ & 0.02 \\
\hline No & $38(6.4 \%)$ & $14(10.9 \%)$ & $24(5.1 \%)$ & Ref & \\
\hline \multicolumn{6}{|l|}{ NAl treatment } \\
\hline$\leqslant 48 \mathrm{~h}$ symptom onset & $136(23.7 \%)$ & $19(15.2 \%)$ & $117(26.0 \%)$ & $0.26(0.11-0.61)$ & 0.002 \\
\hline$>48 \mathrm{~h}$ symptom onset & $401(69.7 \%)$ & $92(73.6 \%)$ & $309(68.7 \%)$ & $0.49(0.24-0.99)$ & 0.04 \\
\hline No & $38(6.6 \%)$ & $14(11.2 \%)$ & $24(5.3 \%)$ & Ref & \\
\hline \multicolumn{6}{|l|}{ NAI treatment } \\
\hline$\leqslant 3$ days symptom onset & $207(36.0 \%)$ & $38(30.4 \%)$ & $169(37.6 \%)$ & $0.37(0.17-0.79)$ & 0.01 \\
\hline$>3$ days symptom onset & $330(57.4 \%)$ & $73(58.4 \%)$ & $257(57.1 \%)$ & $0.46(0.22-0.95)$ & 0.04 \\
\hline No & $38(6.6 \%)$ & $14(11.2 \%)$ & $24(5.3 \%)$ & Ref & \\
\hline \multicolumn{6}{|l|}{ NAl treatment } \\
\hline$\leqslant 4$ days symptom onset & $268(46.6 \%)$ & $51(40.8 \%)$ & $217(48.2 \%)$ & $0.39(0.18-0.81)$ & 0.01 \\
\hline >4 days symptom onset & $269(46.8 \%)$ & $60(48.0 \%)$ & $209(46.4 \%)$ & $0.47(0.23-0.97)$ & 0.04 \\
\hline No & $38(6.6 \%)$ & $14(11.2 \%)$ & $24(5.3 \%)$ & Ref & \\
\hline \multicolumn{6}{|l|}{ NAI treatment } \\
\hline$\leqslant 5$ days symptom onset & $338(58.8 \%)$ & $63(50.4 \%)$ & $275(61.1 \%)$ & $0.38(0.18-0.78)$ & 0.01 \\
\hline$>5$ days symptom onset & $199(34.6 \%)$ & $48(38.4 \%)$ & $151(33.6 \%)$ & $0.52(0.24-1.09)$ & 0.08 \\
\hline No & $38(6.6 \%)$ & $14(11.2 \%)$ & $24(5.3 \%)$ & Ref & \\
\hline
\end{tabular}

NAI, neuraminidase inhibitors.

those with the influenza B virus [23]. In the Canadian study by McGeer et al., NAI treatment was also more frequently administered to influenza A patients [8]. This may be because clinicians know that excess mortality is higher when one of the virus A subtypes (H3N2 subtype) predominates [3].
The multivariable analysis showed that NAI were effective in avoiding death in hospitalised patients when administered within the $48 \mathrm{~h}$ following symptom onset (aOR $0.37,95 \%$ CI $0.22-0.63$ ) and less effective in avoiding death when administered $\geqslant 48 \mathrm{~h}$ after symptom onset (aOR $0.62,95 \%$ CI $0.40-0.97$ ) (Table 4 ). This is in 
Table 4. Crude and adjusted OR of NAI treatment in reducing the mortality in hospitalised patients and patients admitted to the intensive care unit, Catalonia, 2010-2016

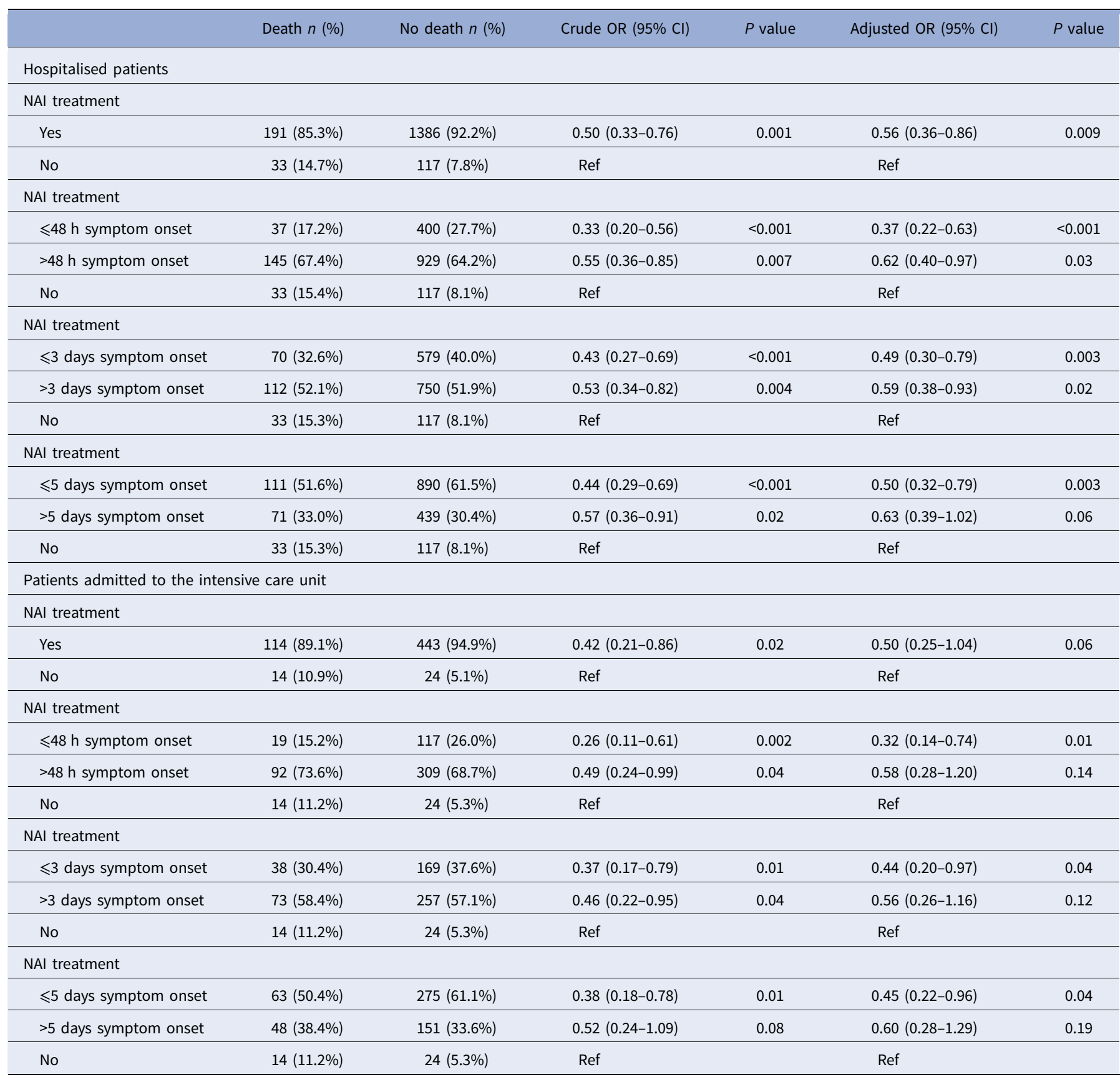

$\mathrm{NAl}$, neuraminidase inhibitors.

agreement with other studies. Hiba et al. in Israel in 2009-2010 compared patients hospitalised due to influenza who received $\mathrm{NAI} \leqslant 48$ and $>48 \mathrm{~h}$ after symptom onset and found that mortality was higher in patients with delayed treatment [24]. In a Hong Kong study by Lee et al. [25], carried out between January 2007 and December 2008 , early NAI treatment $(\leqslant 48 \mathrm{~h})$ was associated with better survival. In Spain, the study by Delgado-Rodríguez et al. [26] in 2009-2010 found that NAI were only effective in avoiding death or ICU admission when administered $\leqslant 48 \mathrm{~h}$, with an aOR of 0.46 (95\% CI $0.27-0.80)$, close to that obtained in our study.

A meta-analysis of subjects included in observational studies concluded that, compared with no treatment, NAI administered at any time were associated with a reduced risk of mortality (OR $0.81,95 \%$ CI $0.70-0.93$ ), and for early treatment $(\leqslant 48 \mathrm{~h}$ ) the OR was 0.50 (95\% CI 0.37-0.67) [27].

In our study, the aOR of early NAI treatment ( $\leqslant 48 \mathrm{~h}$ after symptom onset) in avoiding death in patients admitted to the ICU was 0.32 (95\% CI 0.14-0.74) (Table 4), lower than the 0.44 (95\% CI 0.21-0.87) obtained in another Spanish study carried out in 2010-2011 [28]. In the US study by Shah et al. [20] in ICU patients in 2013-14, adult age was associated with death, as in the present study, but NAI administered $\leqslant 48 \mathrm{~h}$ were not associated with survival.

The Hong Kong study by Lee et al. found that higher viral loads correlated with more severe symptoms. They pointed out 
that, in high-risk patients with severe symptoms, the viral load may remain high for longer, and therefore late initiation of NAI treatment may still be worth considering [29].

One important finding of the present study is that death was avoided not only in all severe hospitalised patients and patients admitted to the ICU who received NAI in the first $48 \mathrm{~h}$ after symptom onset but also, although to a lesser extent, in patients who received NAI within 3 days after symptom onset and 5 days after symptom onset. In the study by Louie et al., critically ill patients with $\mathrm{A}(\mathrm{H} 1 \mathrm{~N} 1)$ pdm09 who received NAI within 5 days after symptom onset had better survival than patients who did not receive NAI [30]. As McGeer et al. [8] point out, these findings do not contradict data from healthy adult studies demonstrating that treatment should be started sooner than $48 \mathrm{~h}$ after symptom onset in order to reduce the duration of symptoms and severity of illness $[3,31]$. In the present study, most patients presented comorbidities and because, in immunocompromised patients, viral replication lasts longer than in healthy patients, in many of these patients, treatment might have had an effect on the progression of the disease and on avoiding death (see Supplementary Table S3).

Our results also suggest a certain dose-response relationship between the effectiveness of NAI in avoiding death and the days from symptom onset to the initiation of treatment. These results are in accordance with the findings of Louie et al. [30], who observed a trend toward improved survival in patients receiving the earliest treatment.

This study, like all observational studies, has strengths and limitations. One strength is that few studies have investigated the effectiveness of NAI in adult hospitalised patients, and therefore, our results may help identify factors associated with the suboptimal use of antiviral treatment in diminishing the burden of influenza disease in adults, while an RCT that could demonstrate causality would be difficult for ethical reasons [28]. A second strength is that all cases included were laboratory-confirmed, and accordingly, we were able to investigate the effect of antiviral treatment in avoiding death due to influenza virus. Finally, the sample size permitted a multivariable analysis and therefore reduced the possibility of confounding factors invalidating the results.

The study has also limitations. First, hospitals participated voluntarily, which could lead to selection bias [21, 28, 30, 32]. However, because the hospitals participating in the surveillance system cover more than $60 \%$ of the population of Catalonia and we used a mixed-effect logistic regression model with hospitals as a random intercept, we believe that our results may be extensible to severe hospitalised patients in Catalonia. Second, unmeasured confounders, such as the characteristics of unmeasured comorbidities, might have altered the results. Third, untreated patients may have been less severely ill than patients treated with NAI, because the decision to treat with NAI may have been influenced by clinicians' perceptions of disease severity [30]. The final adjusted model was constructed taking into account the propensity score built with variables that included the most important comorbidities, and it seems unlikely that the results suffered a large bias. Nevertheless, some residual confounding cannot be ruled out. Finally, because the subjects studied were severe hospitalised patients, the results cannot be extrapolated to outpatients or non-severe patients.

In conclusion, our results show that NAI treatment had a protective effect in avoiding death in patients hospitalised due to severe influenza and those admitted to the ICU. The effect was greater when administered $\leqslant 48 \mathrm{~h}$ after symptom onset but also when no more than 5 days since symptom onset had elapsed.

Supplementary material. The supplementary material for this article can be found at https://doi.org/10.1017/S0950268818000663

Acknowledgement. The Surveillance of Hospitalized Cases of Severe Influenza in Catalonia Working Group is composed of: Alsedà M, Álvarez J, Arias C, Balañà PJ, Barrabeig I, Camps N, Carol M, Ferràs J, Ferrús G, Follia $\mathrm{N}$, Godoy P, Bach P, Jané M, Martínez A, Minguell S, Parrón I, Plasència E, Sala-Farré MR, Torner N, Torra R, Torres J (Public Health Agency of Catalonia); Caylà J, Gorrindo P, Rius C (Public Health Agency of Barcelona); Marcos MA, Mosquera MDM, Vilella A (H Clínic, Barcelona); Antón A, Pumarola T, Campins M (H Universitari Vall d'Hebrón, Barcelona); García D (H Josep Trueta, Girona); Espejo E (H Terrassa); Freixas N, Riera Garcia M (Mútua Terrassa); Maraver E, Mas D, Perez R, (H Altahia Manresa); Rebull J (H.Verge de la Cinta, Tortosa); Pou J (H Sant Joan de Déu, Esplugues); García-Pardo G, Olona M (H Joan XXIII, Tarragona); Barcenilla F, Castellana D (H Arnau de Vilanova, Lleida) Navarro-Rubio G (Consorci Sanitari Parc Taulí, Sabadell); Force LL (H Mataró).

Financial support. This study was supported by the Programme of Surveillance, Prevention and Control of Transmissible Diseases (PREVICET) of CIBER de Epidemiología y Salud Pública (CIBERESP), Instituto de Salud Carlos III, Madrid.

Conflict of interest. None.

\section{References}

1. World Health Organization. Questions and answers on immunization and vaccine safety. Available at http://www.who.int/features/qa/84/en/.

2. World Health Organization. Fact sheet on influenza. Available at http:/ www.who.int/mediacentre/factsheets/fs211/en/.

3. Treanor JJ (2015) Influenza (including avian influenza and swine influenza. In Bennet JE, Dolin R and Blaser MJ (eds). Principles and Practice of Infectious Diseases, 8th edn., Philadelphia, PA: Elsevier, pp. 2000-2024.

4. Harper SA, et al. (2009) Seasonal influenza in adults and childrendiagnosis, treatment, chemoprophylaxis, and institutional outbreak management: clinical practice guidelines of the Infectious Disease Society of America. Clinical Infectious Disease 48, 1003-1032.

5. Spagnuolo PJ, et al. (2016) Effects of antiviral treatment on influenzarelated complications over four influenza season: 2006-2010. Current Medical Research and Opinion 32, 1399-1407.

6. Lindegren ML, et al. (2015) Antiviral treatment among older adults hospitalized with influenza, 2006-2012. PLoS ONE 10, e0121952.

7. Agència de Salut Pública de Catalunya. Pla d'actuació a Catalunya enfront d'una infecció per virus de la grip en fase post-pandèmica. Available at http://canalsalut.gencat.cat/web/.content/home_canal_salut/ professionals/temes_de_salut/grip/documents/grippostpan2010.pdf (Accessed 28 November 2017).

8. McGeer A, et al. (2007) Antiviral therapy and outcomes of influenza requiring hospitalization in Ontario, Canada. Clinical Infectious Disease 45, 1568-1575.

9. Martin ET (2017) Use of neuraminidase inhibitors for treatment of severe influenza: times are changing. Clinical Infectious Disease 64, 368-369.

10. Michiels B, et al. (2013) The value of neuraminidase inhibitors for the prevention and treatment of seasonal influenza: a systematic review of systematic reviews. PLoS ONE 8, e60348.

11. Hsu J, et al. (2012) Antivirals for treatment of influenza: a systematic review and meta-analysis of observational studies. Annals of Internal Medicine 156, 512-524.

12. Lindegren ML and Schaffner W (2014) Treatment with neuraminidase inhibitors for high-risk patients with influenza: why is adherence to antiviral treatment recommendations so low? The Journal of Infection Disease 210, 510-513.

13. Agència de Salut Pública de Catalunya. Estratègia de Vigilància dels casos greus produïts per la infecció pel virus de la grip. Available at 
http://canalsalut.gencat.cat/web/.content/contingut_responsiu/salutAZ/G/ Grip/documents/arxius/estrategia.pdf (Accessed 28 November 2017).

14. Centro Nacional de Epidemiología. Vigilancia de casos graves hospitalizados confirmados de virus de la gripe. Available at http://www.isciii.es/ISCIII/es/ contenidos/fd-servicios-cientifico-tecnicos/fd-vigilancias-alertas/fd-enfermedades/Vigilancia_de_casos_graves_confirmados_de_virus_de_la_gripe_v. 08octubre2014.pdf (Accessed 28 November 2017).

15. Suwannakarn K, et al. (2008) Typing (A/B) and subtyping (H1/H3/H5) of influenza A viruses by multiplex real-time RT-PCR assays. Journal of Virological Methods 152, 25-31.

16. Katz MH (2011) Multivariable Analysis, 3rd edn., Cambridge, CBG: Cambridge University Press, pp. 88-92.

17. Appiah GD, et al. (2017) Increased antiviral treatment among hospitalized children and adults with laboratory-confirmed influenza, 20102015. Clinical Infectious Disease 64, 364-367.

18. Fernández S, et al. (2012) Analysis of confirmed severe cases of influenza in the first season after pandemic. Medicina Clinica 139, 84-87.

19. Maruyama T, et al. (2016) Outcomes and prognostic features of patients with influenza requiring hospitalization and receiving early antiviral therapy: a prospective multicentre cohort study. Chest 149, 526-534.

20. Shah NS, et al. (2015) Severe influenza in 33 US hospitals, 2013-2014: complication and risk factors for death in 507 patients. Infection Control and Hospital Epidemiology 36, 1251-1260.

21. Xu C, et al. (2013) Characteristics of hospitalized cases with influenza A (H1N1)pdm09 infection during first winter season of post-pandemic in China. PLoS ONE 8, e55016.

22. Rolfes MA, et al. (2016) Respiratory viral testing and influenza antiviral prescriptions during hospitalization for acute respiratory illness. Open Forum Infectious Disease 3, ofv216.
23. Gutiérrez-Pizarraya A, et al. (2012) Unexpected severity of cases of influenza B infection in patients that required hospitalization during first postpandemic wave. The Journal of Infection 65, 423-430.

24. Hiba V, et al. (2011) Benefit of early treatment with oseltamivir in hospitalized patients with documented 2009 influenza A (H1N1): retrospective cohort study. The Journal of Antimicrobial Chemotherapy 66, 1150-1155.

25. Lee N, et al. (2010) Outcomes of adults hospitalised with severe influenza. Thorax 65, 510-515.

26. Delgado-Rodríguez M, et al. (2012) Prognosis of hospitalized patients with 2009 H1N1 influenza in Spain: influence of neuraminidase inhibitors. The Journal of Antimicrobial Chemotherapy 67, 1739-1745.

27. Muthuri SG, et al. (2014) Effectiveness of neuraminidase inhibitors in reducing mortality in patients admitted to hospital with influenza H1N1pdm09 virus infection: a meta-analysis of individual participant data. The Lancet. Respiratory Medicine 2, 395-404.

28. Rodríguez A, et al. (2011) Impact of early oseltamivir treatment on outcome in critically ill patients with 2009 pandemic influenza A. The Journal of Antimicrobial Chemotherapy 66, 1140-1149.

29. Lee N, et al. (2013) Influenza virus load in hospitalized patients. Hong Kong Medical Journal 19, 15-18.

30. Louie JK, et al. (2012) Treatment with neuraminidase inhibitors for critically ill patients with influenza $\mathrm{A}(\mathrm{H} 1 \mathrm{~N} 1) \mathrm{pdm} 09$. Clinical Infectious Disease 55, 1198-1204.

31. Yu H, et al. (2010) Effectiveness of oseltamivir on disease progression and viral RNA shedding in patients with mild pandemic 2009 influenza A H1N1: opportunistic retrospective study of medical charts in China. British Medical Journal 341, c4779.

32. Ayscue P, et al. (2014) Influenza-associated intensive-care unit admissions and deaths - California, September 29, 2013-January 18, 2014. MMWR Morbidity and Mortality Weekly Report 63, 143-147. 